\title{
Impacto de la educación financiera en la tasa de ahorro para el retiro (Impact of Financial Education on the Retirement Savings Rate)
}

\section{'Aarón González Vázquez ii Azucena Alejandra Aceves Alós iii Daniel Prado Mendoza}

Summary. The present study shows the influence of education and financial knowledge of Nuevo Leon, especially those living in the metropolitan area of Monterrey, in their deliberate decision to save for retirement. It reflects on the challenge posed to the new society by the demographic change that is aging the population pyramid. It addresses the great opportunity offered by the demographic bonus, called "the window of opportunity", as well as the current situation of saving in the population. It shows briefly the impact that education has on the development of the person, as well as financial education to make better decisions in life. Finally, the results of financial education in a segment of Monterrey, Nuevo León, Mexico, are shown and discussed.

Key words: financial education, retirement savings rate.

JEL: I21, G23.

Resumen. En el presente estudio se expone el grado de influencia que ejerce la educación y conocimiento financiero que tienen los nuevoleoneses, en especial quienes viven en la zona metropolitana de Monterrey, en su decisión deliberada de ahorrar para su retiro. Se reflexiona sobre el reto que representa para la nueva sociedad el cambio demográfico que está envejeciendo la pirámide poblacional. Se aborda el tema de la gran oportunidad que nos ofrece el bono demográfico, llamado "la ventana de oportunidad", así como de la situación actual del ahorro en la población. Se muestra brevemente el impacto que tiene la educación en el desarrollo de la persona, así como la educación financiera para tomar mejores decisiones en la vida. Finalmente, se muestran y discuten los resultados que tiene la educación financiera en un segmento de la sociedad de Monterrey, Nuevo León, México.

Palabras claves: educación financiera, tasa de ahorro para el retiro.

\footnotetext{
' Universidad Autónoma de Nuevo León, Facultad de Ciencias Físico Matemáticas, San Nicolás de los Garza, N.L., México. Correo: aaronglzv@gmail.com

"Universidad Autónoma de Nuevo León, Facultad de Ciencias Físico Matemáticas, San Nicolás de los Garza, N.L., México. Correo: aa69mx@yahoo.com

iii Universidad Autónoma de Nuevo León, Facultad de Ciencias Físico Matemáticas, San Nicolás de los Garza, N.L., México. Correo: dprado_mendoza@yahoo.com.mx
} 


\section{Introducción}

Las estructuras piramidales de la población actual en los países del mundo están viviendo un envejecimiento, de modo que la parte alta de la pirámide se está ensanchando y la base se angosta; estos se debe al aumento de la esperanza de vida y la disminución drástica de la natalidad.

A este fenómeno se la llama transición demográfica y presenta retos importantes tanto para los individuos y las familias como para la sociedad y las autoridades gubernamentales, ya que al pasar el tiempo se aumentará el gasto familiar y público destinado al sostenimiento de los adultos mayores, lo cual significará un gran reto para los planes de ahorro para el retiro ya sea personales, privados o públicos.

La carga económica que significa la transición demográfica sobre las finanzas públicas se ha atenuado, en parte, con las reformas a la ley de seguridad social, la cual hace responsable a cada persona de hacer un ahorro durante toda su vida productiva que le permita vivir dignamente en su etapa de vejez o cuando deja de laborar, sin embargo, se observa que en la realidad de los últimos 20 años transcurridos pocas personas están conscientes de ello y no están realizando un ahorro voluntario que les permita sostenerse en su edad avanzada, tan solo están acumulando los recursos que por ley el gobierno está obligado aportar, así como la parte con la que contribuye la empresa en que labora el individuo y la aportación que realiza la persona con el descuento que se realiza obligatoriamente a su sueldo.

Por lo anterior, el gobierno ha iniciado un esfuerzo de comunicación con la población para concientizarla y además ha comenzado un esfuerzo que ha llamado educación financiera.

Considerando lo analizado, se realizó una investigación para corroborar el impacto que tiene la educación financiera sobre la decisión que tiene cada individuo de ahorrar, es decir, el impacto de la educación financiera en la tasa de ahorro para el retiro. Con la investigación se pretende abrir paso a otras alternativas de solución concomitantes con los esfuerzos que ya se realizan en diferentes instancias, la investigación busca conocer la eficacia que logra la educación financiera como un motor para aumentar el ahorro personal, por lo que se establece en el presente estudio la siguiente hipótesis: "Una mayor educación financiera de la persona influye positiva y significativamente en una mayor tasa de ahorro para el retiro de esa persona". 
Es importante mencionar que la educación financiera ha sido definida por la Organización para la Cooperación y Desarrollo Económico (OCDE) como una habilidad para la vida (life skill). A nivel internacional, existe la preocupación por el bajo nivel de educación financiera y la falta de concientización de los ciudadanos. Nuestro país no está exento de esta deficiencia.

\section{Declaración del problema}

Es muy significativo para todos los países del mundo el reto que deberán resolver por el envejecimiento de la pirámide poblacional, lo que ocasiona que cada vez una mayor cantidad de recursos se deberán destinar al sostenimiento de los adultos mayores de 65 años, tanto recursos públicos como privados. Se deberán llevar a cabo medidas rápidas, efectivas y drásticas para que no se pierda el tiempo que tenemos por la ventana de oportunidad llamada bono demográfico.

Algunos datos relevantes que muestran el esfuerzo que toda la población realizará para sostener a una población creciente de adultos mayores, es el indicador de personas dependientes, que es el cociente resultante de dividir la cantidad de niños menores de 15 años y adultos mayores de 65, entre la población en edad laborable. El indicador de personas dependientes en México pasará de 48 dependientes por 100 personas en edad laborable en el año 2015, a 62 personas dependientes en el año 2050.

La transición demográfica se debe a la disminución drástica de la natalidad, por la mayor cantidad de mujeres incorporadas al mercado laboral y por un esfuerzo de comunicación alto por parte del gobierno en el sentido de que la familia pequeña tiene un mejor nivel de vida, lo que se refleja en un decremento de la tasa global de fecundidad en México, la cual pasó de 7.1 hijos tenidos por una mujer a lo largo de su vida en el año 1960 a 1.9 hijos tenidos por una mujer en el año 2014.

Otro factor importante del envejecimiento es el aumento en la esperanza de vida de las personas gracias a una mejor atención médica en México, lo que se refleja en que el indicador aumentó de 32 años en 1921 a 77 años en el 2010 y se espera que se ubique 82 años en el 2050. Por esto, los adultos mayores de 60 años en México pasarán de ser un $6.8 \%$ en el año 2000 a un $28 \%$ en el año 2050.

El problema financiero se agudiza al considerar que actualmente solo el $26 \%$ de la población mayor a 60 años goza de una pensión. Por tal situación, la investigación pretende comprobar el grado de impacto que tiene la educación 
financiera en la tasa de ahorro para el retiro y si pudiera ser una parte de la solución del problema financiero que le significa al país una cada vez mayor proporción de personas dependientes.

El problema que se estudiará en esta investigación es conocer si el nivel de la educación financiera de una población objetivo, descrita en las características de la muestra, es deficiente y pudiera explicarnos o estar relacionada con una baja tasa de ahorro para el retiro. Este será un proyecto de investigación inicial, cuyos resultados nos permitirán abrir oportunidades para realizar otras investigaciones que involucren una mayor cantidad de variables que contribuyan como una parte concomitante a la solución del problema.

\section{Objetivos de la investigación}

Tomando como referencia el contexto económico y social actual de México y los escenarios que se esperan por el comportamiento de su pirámide poblacional, lo que pretende esta investigación como objetivo general es contestar la siguiente pregunta: ¿La educación financiera de la persona ejerce una influencia significativa sobre su tasa de ahorro para el retiro?

Como parte del objetivo general, se pretende conocer si la educación financiera es otra vía alterna y concomitante a los esfuerzos que se realizan para aumentar la tasa de ahorro para el retiro en la población económicamente activa (PEA), de modo que mejore su calidad de vida cuando llegue al estrato de adulto mayor y deje de ser económicamente activa. Como objetivos específicos de la investigación se tienen proyectados los siguientes:

- Conocer el nivel de educación financiera en la muestra seleccionada, a través de la aplicación de una encuesta que se utilizó como instrumento de medición.

- Correlacionar la tasa de ahorro de la muestra seleccionada con su nivel de educación financiera, para conocer si existe una correlación explicativa.

- Generar información técnicamente validada para que sea de utilidad a las autoridades gubernamentales, a las educativas y a las universidades, de modo que les ayude, si lo consideran pertinente, a la creación de políticas coadyuvantes.

- Difundir los resultados en el sector empresarial, por la corresponsabilidad que tiene el empresario con el desarrollo de la comunidad. 


\section{Hipótesis}

Como una predicción teórica que necesita comprobación por medio de la observación y el análisis de datos (Ritchey, 2002), se establece la siguiente hipótesis para la pregunta de investigación: "Una mayor educación financiera de la persona influye positiva y significativamente en una mayor tasa de ahorro para el retiro de esa persona".

\section{Metodología}

Para conocer de manera más precisa los constructos que serán medidos con el fin de aceptar o rechazar la hipótesis de investigación, se muestra la Tabla 1, en la que se especifica la variable independiente del estudio y los valores que puede tomar, y en la Tabla 2 se presenta la información de la variable dependiente.

Tabla 1. Información de la variable independiente

\begin{tabular}{|c|c|c|}
\hline Variable independiente & Valores que toma & Nivel de medición \\
\hline Educación financiera & $\begin{array}{l}\text { Calificación de } 0 \text { a } 100 \text {, sobre un } \\
\text { cuestionario de preguntas que } \\
\text { califica el nivel de conocimiento } \\
\text { financiero del encuestado para la } \\
\text { toma de decisiones personales. }\end{array}$ & Razón \\
\hline
\end{tabular}

Tabla 2. Información de las variables dependientes

\begin{tabular}{lll}
\hline Variable independiente & Valores que toma & Nivel de medición \\
\hline $\begin{array}{l}\text { Tasa de ahorro } \\
\text { para el retiro }\end{array}$ & $\begin{array}{l}\text { Calificación de } 0 \text { a 100, de acuerdo } \\
\text { al porcentaje de ahorro que tenga } \\
\text { con respecto a sus ingresos. }\end{array}$ & Razón \\
\hline
\end{tabular}

Derivado de lo anterior, podemos mencionar que el enfoque de la investigación es cuantitativo porque utiliza los datos capturados a través de un instrumento de recolección con el fin de, posteriormente, analizarlos y descubrir si existe un patrón de comportamiento en la población que nos permita confirmar 0 rechazar la hipótesis y con ello contestar la pregunta de investigación (Hernández, Fernández \& Baptista, 2003). 
El alcance de la investigación consiste en un estudio explicativo porque "está dirigido a responder las causas de los eventos y fenómenos sociales" (Hernández, Fernández \& Baptista, 2003), es decir, se pretende responder si la educación financiera es una causa del comportamiento de la tasa de ahorro para el retiro.

La hipótesis de investigación será transeccional causal porque "el diseño describe relaciones entre dos o más conceptos o variables en un momento determinado" (Hernández, Fernández \& Baptista, 2003), ya que se recolectarán datos en un momento y su propósito será describir el comportamiento de la tasa de ahorro para el retiro en diferentes niveles de educación financiera.

\section{Muestra}

Para aplicar el instrumento de recolección de datos se seleccionó una muestra en el área metropolitana de Monterrey, Nuevo León, México, una ciudad con características homogéneas en cuanto a la educación financiera de sus habitantes y la cultura de ahorro en los miembros de su sociedad.

Con el fin de aumentar la validez externa del experimento, "es conveniente tener grupos lo más parecido posible a la mayoría de las personas a quienes se desea generalizar y repetir el experimento" (Hernández, Fernández \& Baptista, 2003), por lo que se tomó una muestra solo de personas que cumplían con lo siguiente:

- Habitan en el área metropolitana de Monterrey.

- Se encuentren laborando.

- Se encuentren casados o viviendo en unión libre con su pareja.

- Con una edad de 30 a 49 años.

- Con ingresos de 30,000 a 50,000 pesos mensuales.

La muestra se seleccionó considerando la información intercensal del Instituto Nacional de Geografía y Estadística (INEGI, 2015) en el área metropolitana de Monterrey para el año 2015. Se utilizó el factor obtenido de la encuesta intercensal y se aplicó sobre la población informada por el INEGI para los municipios del estado de Nuevo León.

- La población en Nuevo León publicada es de 5,119,504.

- Los habitantes que viven en el área metropolitana son 4,426,388.

- Del grupo anterior, utilizando las proporciones de la encuesta intercensal, se encuentran laborando 1,823,390 personas. 
- De estas últimas, existen 1,195,692 personas que están casadas o que se encuentran con pareja en unión libre.

- Con las características anteriores y que tengan una edad de 30 a 49 años, se encuentran 708,756 personas.

- Del grupo anterior, solo hay 22,417 personas que tiene un ingreso que se encuentra en el rango de 30,000 a 50,000 pesos mensuales.

La muestra se tomó aleatoriamente con el propósito de que variables extrañas, conocidas o desconocidas, no afecten de manera sistemática los resultados del estudio. Como menciona Cochran (Cochran \& Cox, 1992), la aleatorización es en cierta forma análoga a un seguro.

El cálculo del tamaño de la muestra es una función matemática que expresa la relación entre las variables, cantidad de participantes y poder estadístico. Dado que se desea estudiar la correlación de la tasa de ahorro para el retiro con la educación financiera, se utiliza un valor de $p=0.5$ como representante de la población y por lo tanto se asume la máxima variación posible en la población.

El tamaño adecuado de muestra $(n)$ se calculó con un error de estimación (E) del $10 \%$ y un grado de confianza del $95 \%$, quedando como sigue:

$$
n=\left(z^{2} p q\right) / E^{2}
$$

Si tomamos de base que $p=0.5$ y $q=0.5$ obtenemos que:

$$
\begin{gathered}
n=\left(1.64^{2} \times 0.5 \times 0.5\right) /\left(0.1^{2}\right) \\
n=68
\end{gathered}
$$

\section{Herramienta estadística}

La herramienta estadística que se aplicó a los datos que se recolectaron fue el modelo de regresión lineal para estimar el efecto de una variable sobre otra. La variable dependiente fue la tasa de ahorro para el retiro y la variable independiente fue la educación financiera. 


\section{Instrumento de recolección de datos}

La recolección de datos fue a través de un cuestionario que se aplicó a 263 personas que trabajan en el área metropolitana de Monterrey y, de estas, se escogieron aquellas que tienen las características que se encuentran definidas en el perfil de la muestra.

El cuestionario tuvo, tanto en su variable dependiente como en su variable independiente, una medición de razón en sus escalas, ya que incluyó un número en la escala de 0 a 100.

Se capacitó con mucho detalle a los encuestadores para que los resultados reflejarán el efecto de la variable independiente sobre la variable dependiente. Para medir la variable independiente, educación financiera, se aplicó un cuestionario con 25 preguntas sobre temas financieros cotidianos en los que el grado de dificultad aumenta al ir avanzando en las preguntas.

\section{Marco teórico}

La metodología de búsqueda fue obtener información publicada en libros del tema, revistas especializadas, artículos y disertaciones. En la lectura y el análisis de la información localizada se seleccionaron los materiales con mayor peso específico para el estudio.

\section{El cambio demográfico en el mundo}

El cambio demográfico que está viviendo el mundo se fundamenta principalmente en el aumento de la esperanza de vida de la población y en el abatimiento de la tasa de natalidad.

Estos cambios se han presentado mayormente en el mundo desarrollado, en donde la esperanza de vida es más alta por la avanzada atención médica que tienen disponible y en una tasa de natalidad menor porque las mujeres están integradas, en su mayoría, al mercado de trabajo, de modo que las parejas deciden tener menos hijos con el fin de poder desarrollar todo su potencial profesional, así como canalizar el tiempo y los recursos disponibles entre un número menor de hijos.

Se puede apreciar en la Figura 1 la tasa global de fecundidad en el mundo por grado de desarrollo regional y en la Figura 2 se observa la esperanza de vida 
clasificada también de acuerdo al nivel de desarrollo. Son notorias las diferencias abismales entre el mundo más desarrollado y el mundo menos desarrollado en este momento.

Comparando las curvas, se puede observar que en el año 2000, en la región más desarrollada, se tenía una tasa de natalidad de 1.6 hijos por mujer y en la región menos desarrollada de 5.2 hijos por mujer. En tanto que en la esperanza de vida se observa que en el año 2000 de la región más desarrollada tenía 76 años de esperanza y en la región menos desarrollada era de 49 años.

La tendencia que se está presentando es que la brecha entre las curvas se está cerrando según avanza el tiempo, ya que la tasa de natalidad que se espera en el mundo menos desarrollado en el año 2050 es de 2.5 hijos por mujer y una esperanza de vida de 67 años.

Figura 1. Tasa global de fecundidad según región, 1950-2050

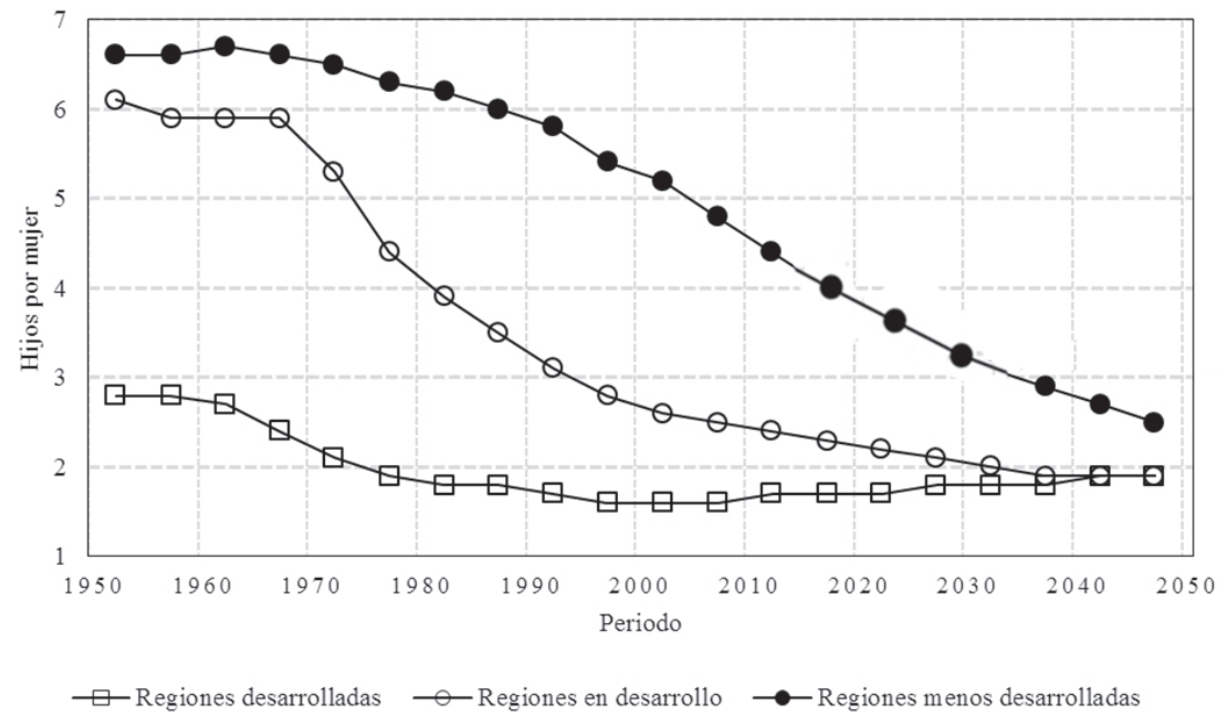

Fuente: Population Division of the Department of Economic and Social Affairs of the United Nations Secretariat. (2002). 
Figura 2. Esperanza de vida al nacimiento según región, 1950-2050

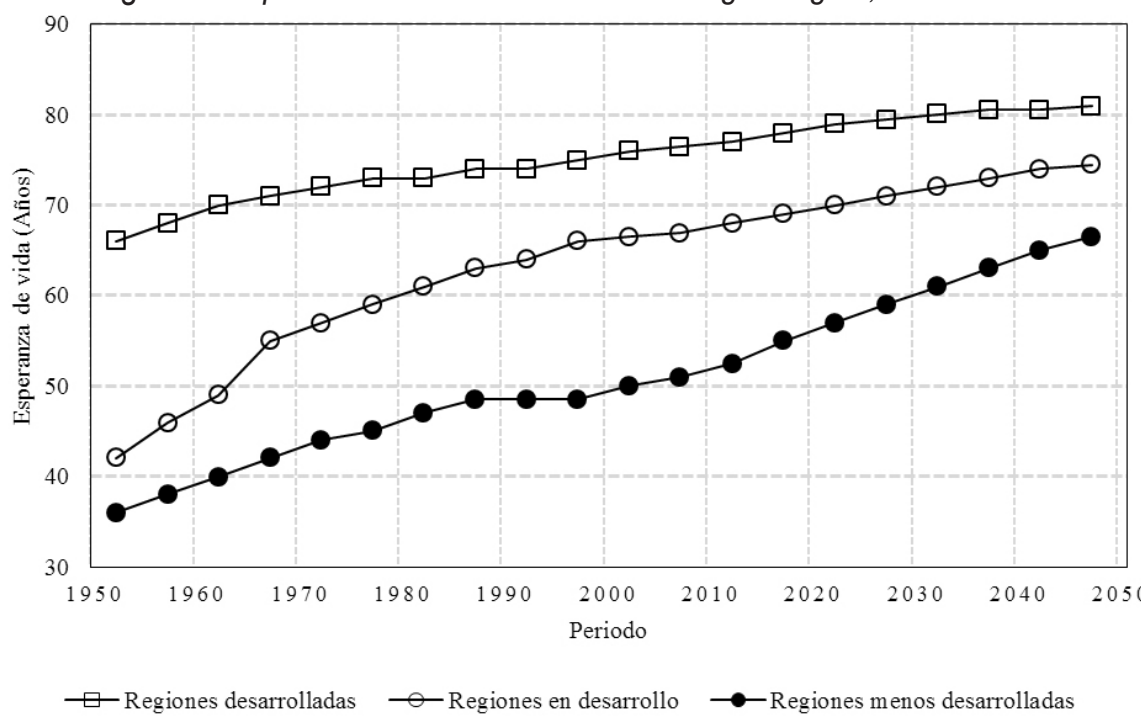

Fuente: Population Division of the Department of Economic and Social Affairs of the United Nations Secretariat. (2002).

Si juntamos las curvas de todas las regiones, se advierte en la Figura 3 que la población agregada está experimentando un envejecimiento acelerado a partir del año 2000, debido a una mayor cantidad de personas con más de 60 años y una cantidad de niños y jóvenes que casi se mantiene al mismo nivel.

Figura 3. Distribución de la población por grandes grupos de edad, 1950-2050

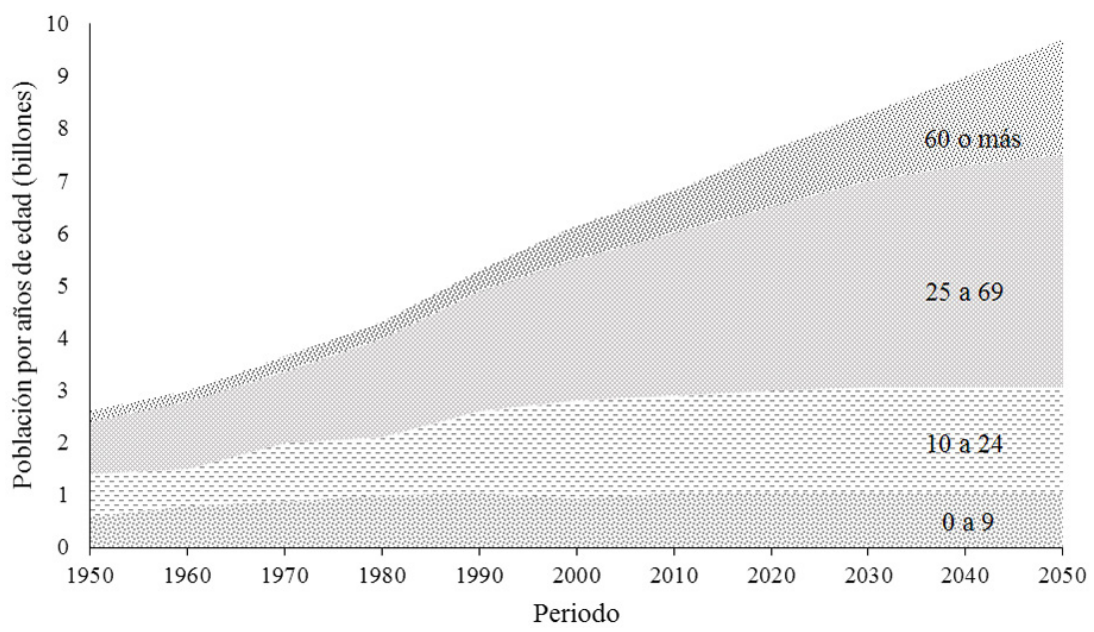

Fuente: Population Division of the Department of Economic and Social Affairs of the United Nations Secretariat. (2012). 


\section{El cambio demográfico en México}

Por las mismas razones comentadas en el cambio demográfico mundial, en México también se presenta una drástica disminución de la natalidad, como se observa en la Figura 4, derivado de una intensa campaña gubernamental en la que se comunicó incesantemente que la familia pequeña vive mejor. También el país está experimentando un aumento muy importante en la esperanza de vida por la mayor cobertura de servicios médicos en la población, como se observa en la Figura 5.

Los adelantos médicos también han inducido una transición epidemiológica que se refiere a la evolución de las principales causas de muerte, pasando de causas originadas por enfermedades infecciosas a causas originadas por enfermedades crónicas y degenerativas, propias de una población envejecida.

Se puede apreciar que la esperanza de vida promedio pasó de 58 años en 1960, a 77 en años recientes, esperando que se ubique en 82 años en el 2050. También se ve con claridad el abatimiento del índice de natalidad, ya que los hijos por mujer pasaron de 7.1 en el año 1960 a 1.9 en esta última década con un escenario más probable de que se mantenga en este nivel.

Figura 4. Tasa global de fecundidad, 1950-2050

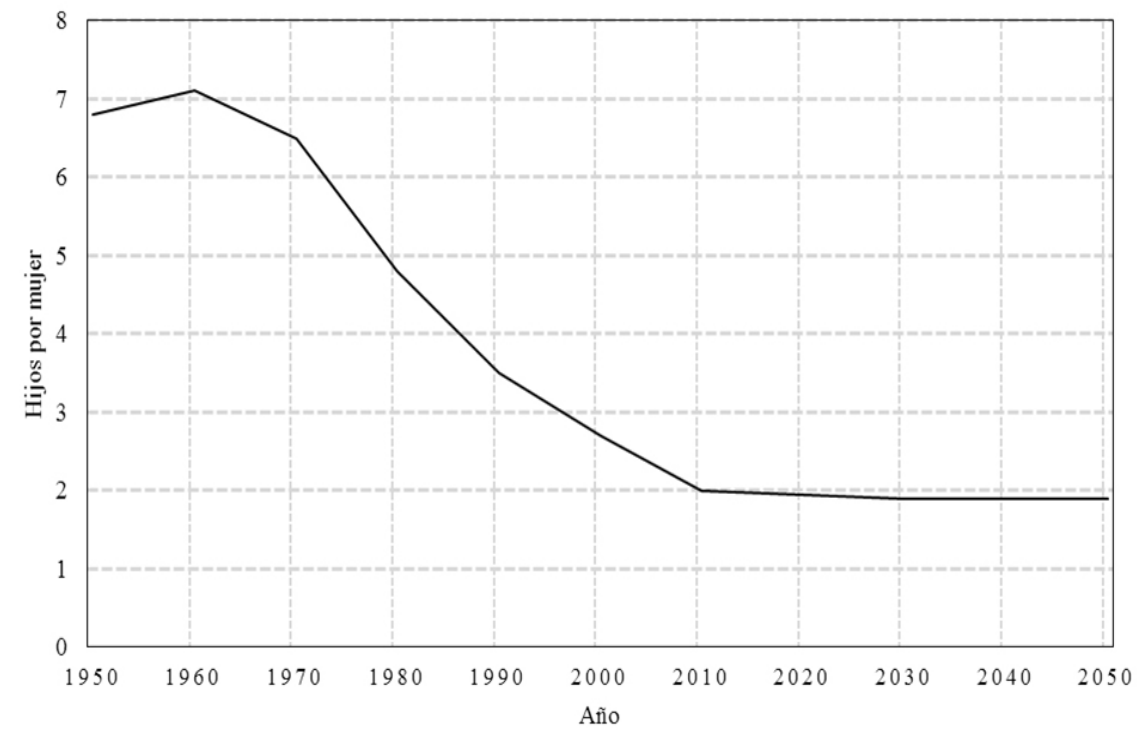

Fuente: Consejo Nacional de Población (2006). 
Figura 5. Esperanza de vida al nacimiento por sexo, 1950-2050

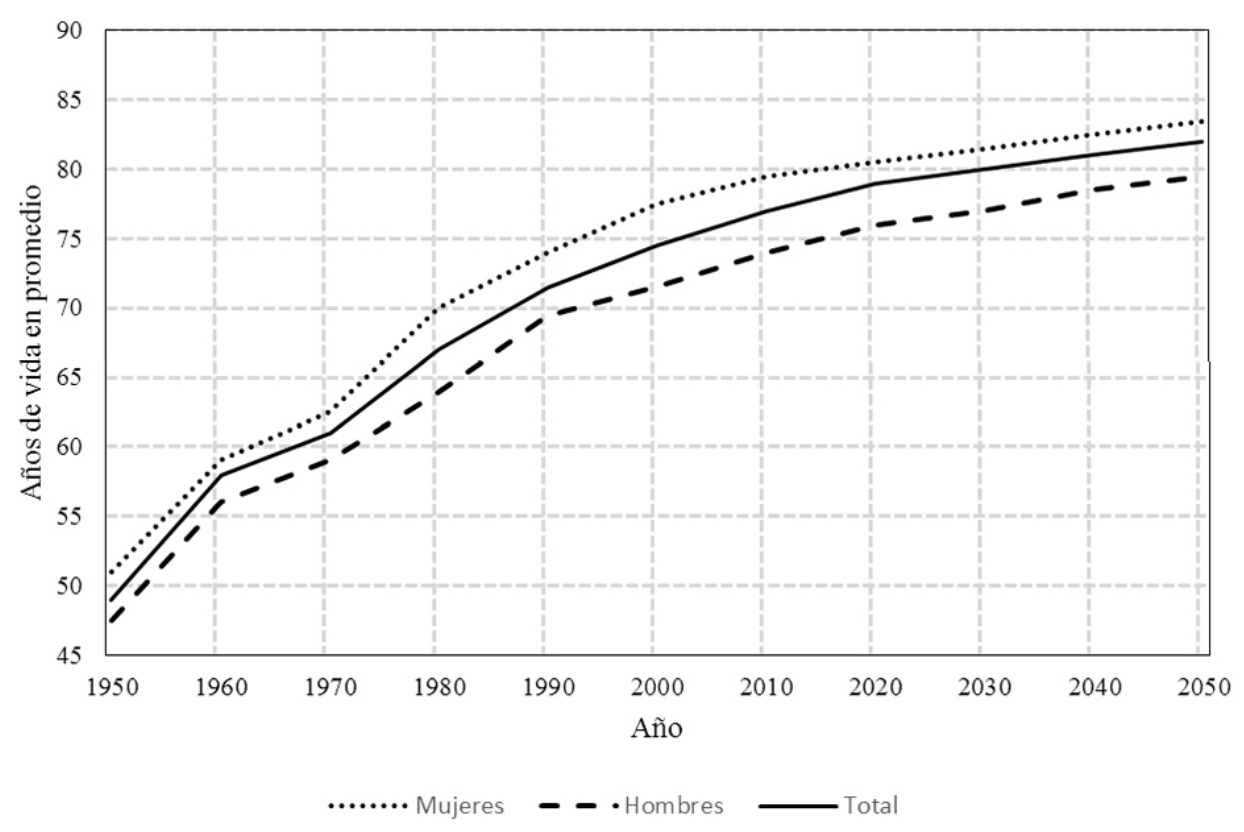

Fuente: Consejo Nacional de Población (2006).

Principalmente por las dos transiciones anteriores, el cambio demográfico en México inició con el aumento de adultos mayores en la década de los años 90, cambiando la forma de la pirámide poblacional, entrando en un proceso de ensanchamiento de la parte alta de la pirámide y un angostamiento de su base, como se muestra en la Figura 6, en la que se compara la pirámide del año 1970 con la proyección de la pirámide para el año 2050.

Lo anterior implica, para el país y la sociedad, una serie de retos:

- (a) el aumento de los montos destinados en el cuidado de adultos mayores, limitará el uso de recursos para otras necesidades de la sociedad

- (b) el envejecimiento de la pirámide implicará dificultades en los presupuestos de los institutos públicos de seguridad social y

- (c) existirá un aumento de los egresos familiares para el cuidado de sus adultos mayores. 
Figura 6. Pirámide de la población de México 1970-2050
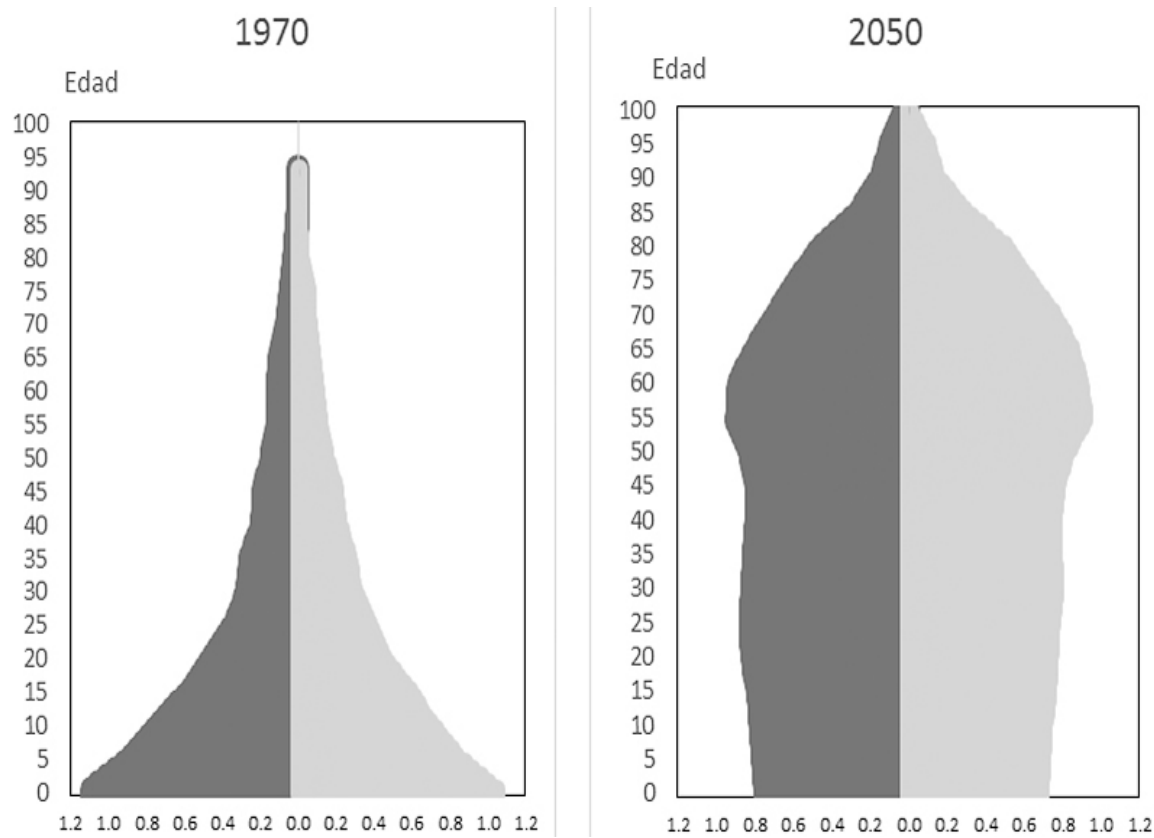

Fuente: Consejo Nacional de Población (2004).

Todo lo anterior implica que el número de personas mayores de 60 años seguirá aumentando; así se aprecia en la Figura 7, pasando de un $5.9 \%$ en el año 1970 a 28 \% en el año 2050. Por lo anterior, la edad media de la población aumentará de 22.4 años en 1970 a 29.8 años en 2010 y a 42.7 años en el 2050.

Figura 7. Distribución de la población de México por grandes grupos de edad, 1950-2050

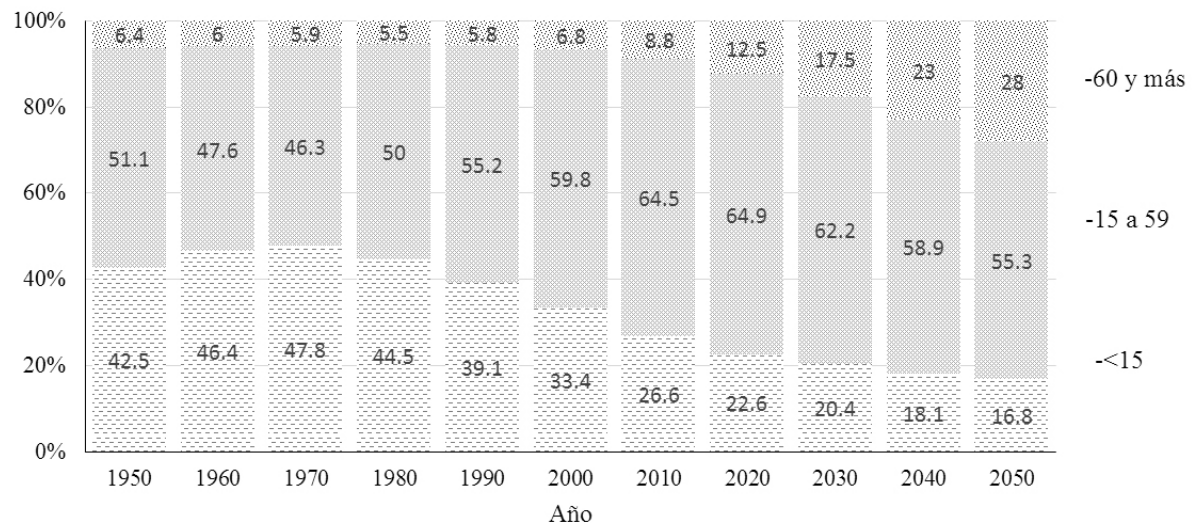

Fuente: Consejo Nacional de Población (2004). 
Otra manera de observar el efecto del envejecimiento poblacional es obteniendo la cantidad de adultos mayores por cada cien niños; actualmente se tienen 48 adultos mayores por cada cien niños, pero en el año 2034 la cantidad de adultos mayores ya alcanzará a ser mayor que la cantidad de niños en el país, de modo tal que en el año 2050 habrá 165 adultos mayores por cada 100 niños. El envejecimiento es notorio.

Figura 8. Índice de envejecimiento de la población en México, 2000-2050

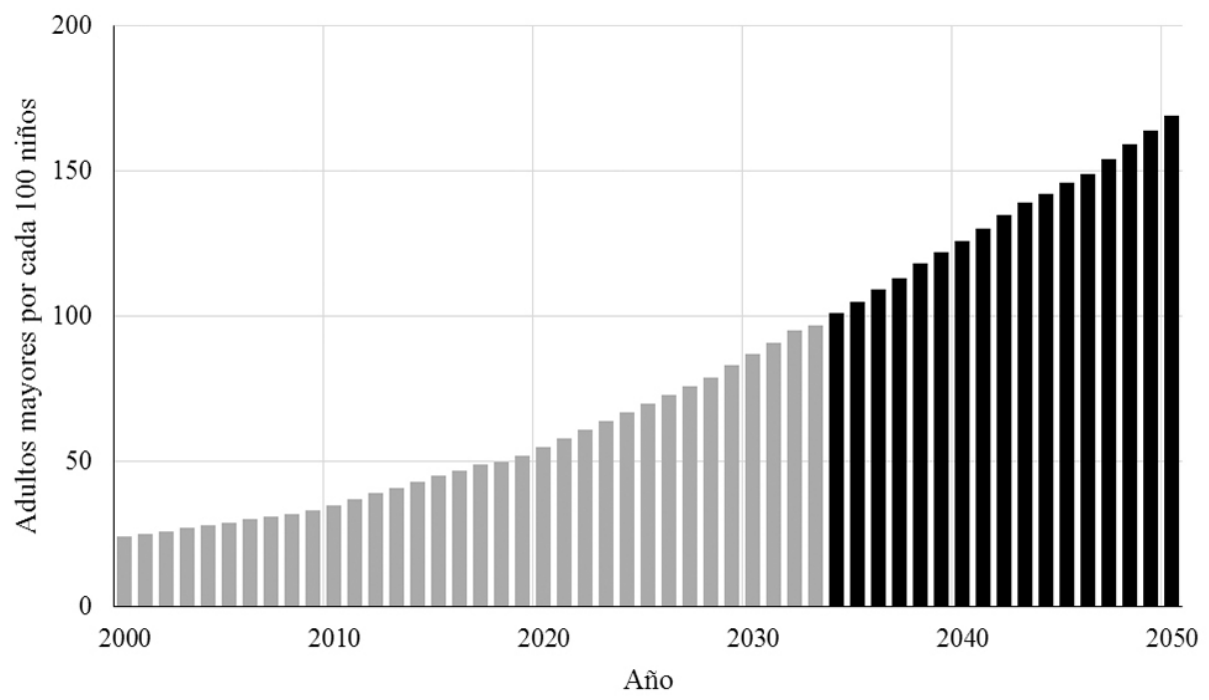

Fuente: Consejo Nacional de Población (2004).

Menciona Partida que: "al paso de altas tasas de mortalidad y natalidad sin control a bajas tasas controladas se le conoce como: transición demográfica" (Partida, 2011).

Si bien el proceso es general en todas las sociedades en términos esquemáticos, las condiciones sociales que lo determinan y el tiempo en que ocurre no solo difiere entre países, sino incluso entre distintas poblaciones dentro de una misma nación (Coales y Watkins, 1986). En la Figura 9 se aprecia la transición demográfica en México: 
Figura 9. Transición demográfica de México, 1930-2050

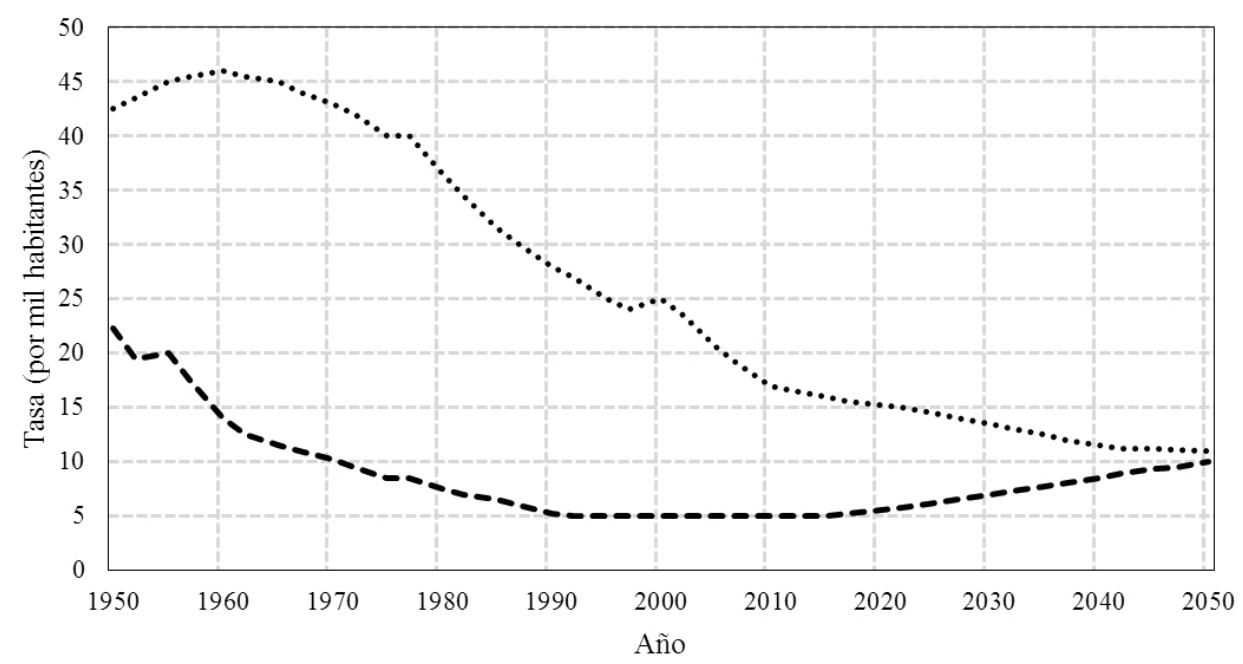

Fuente: Consejo Nacional de Población (2006).

\section{La gran oportunidad del bono demográfico}

La gran oportunidad del bono demográfico, también llamada "ventana de oportunidad", tiene que ver con el hecho de que un gran porcentaje de la población se encuentra económicamente activa, por lo que una parte de este ingreso es utilizado para sufragar los gastos de un bajo porcentaje de personas en edad adulta, existiendo un excedente de recursos que se pueden utilizar para ahorro, lo cual se invertiría en proyectos productivos que generan riqueza, de modo que se crea un círculo virtuoso.

El indicador que nos ayuda a medir esto es el Índice de Dependencia, el cual se obtiene con el cociente resultante de dividir la cantidad de niños menores de 15 años y adultos mayores de 65, entre la población en edad laborable (15 a 64 años). El indicador de personas dependientes pasará de 48 dependientes por 100 personas en edad laborable en el año 2015, a 62 personas dependientes en el año 2050.

En la Figura 10 se muestra el comportamiento de la dependencia demográfica y económica de 1990 a 2050. Las ventajas que ofrece esta situación serán mayores durante el periodo 2012-2030, cuando el índice de dependencia total será menor a 50 personas en edades dependientes por cada 100 en edad laboral. 
A partir del año 2020, el crecimiento de adultos mayores dependientes crecerá con una curva cuya pendiente está sumamente pronunciada.

Figura 10. Índice de dependencia, 1990-2050

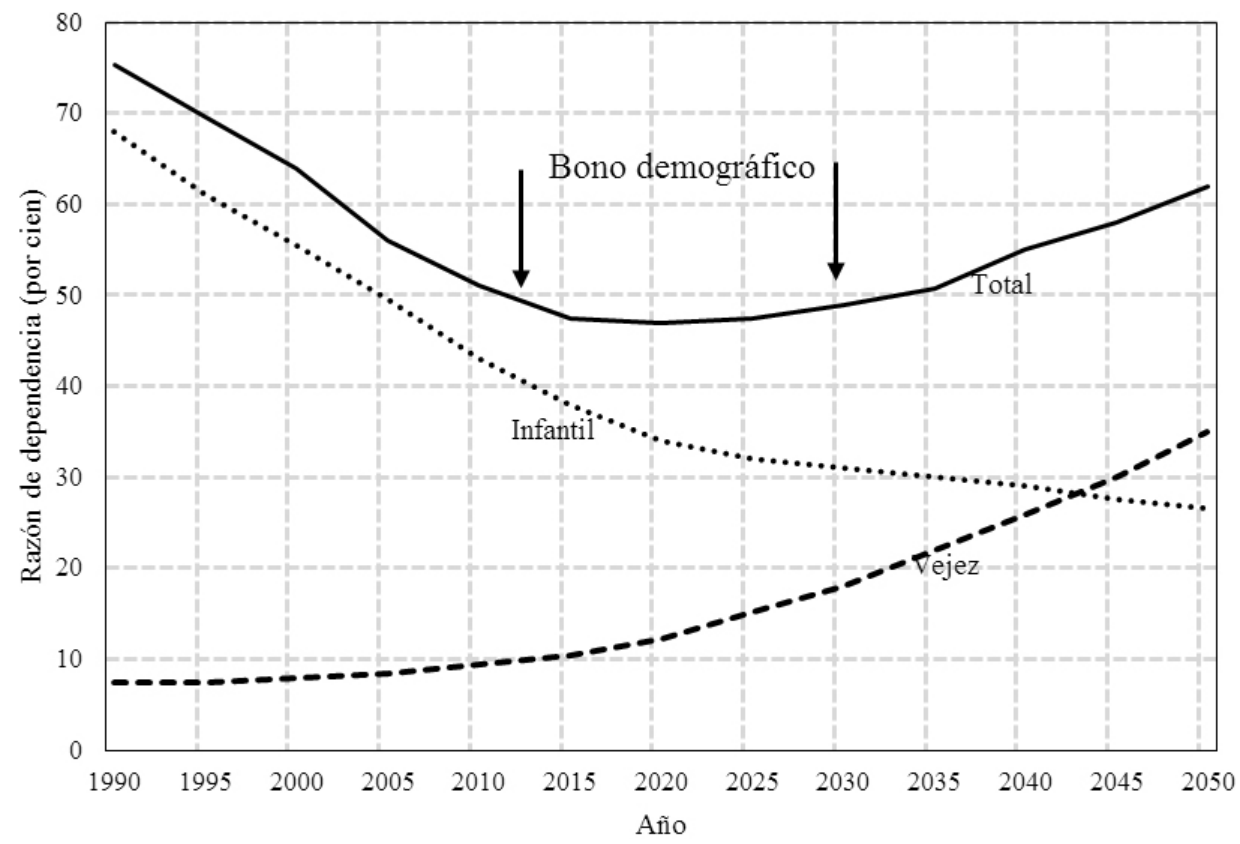

Fuente: CONAPO (2006)

Coale y Hoover (1958) postularon originalmente la hipótesis de que el descenso en la razón de dependencia coadyuvaría a un aumento en el ahorro de las familias, así como en la dirección e intensidad de la inversión pública y privada. La formación de ahorro interno permitirá, asimismo, aliviar la carga de una creciente población de adultos mayores cuando esta ventana ya se haya cerrado (Mason, Lee, Tung, Lai y Miller, 2006).

Resultados en la aplicación de modelos muestran que efectivamente el cambio en la estructura por edad ha tenido una influencia considerable para explicar los aumentos registrados en el producto per cápita de los países asiáticos (Bloom y Williamson, 1998; Bloom et al., 2003).

En México, Mejía y Mojarro (2000) llegan a conclusiones similares al estimar un incremento de 10 puntos porcentuales en la tasa de ahorro de 1990-1994 con respecto al promedio de 1950-1995, el cual se debió al cambio en la composición de la población mexicana. 


\section{Situación actual del ahorro en la población}

La transición demográfica que nos ofrece la ventana de oportunidad llamada bono demográfico, significa un gran reto para los planes de ahorro para el retiro, ya sea privados o públicos.

A partir de las reformas del año 1997, el país cambió de un sistema en que las pensiones se pagaban con los impuestos de los ciudadanos a un sistema de contribuciones definidas y obligatorias que se depositan en cuentas individuales de cada persona laboralmente activa. Este nuevo sistema permite también complementar las aportaciones obligatorias con ahorro voluntario.

Además se promovieron esquemas complementarios para que existan planes privados de ahorro, sin embargo, hay algunos indicadores estadísticos que muestran que un alto porcentaje de la población no participa de los Planes Privados de Pensiones.

La Comisión Nacional del Sistema de Ahorro para el Retiro (CONSAR, 2106) dio a conocer en su reporte anual 2016, sobre los Planes Privados de Pensiones registrados ante esa Comisión, lo siguiente:

- El Sistema de Registro Electrónico de Planes de Pensiones (SIREPP) de CONSAR reporta 2,017 planes registrados, pertenecientes a 1,803 empresas, mismas que ofrecen a sus trabajadores acceso a esquemas voluntarios de ahorro previsional (complementarios al sistema obligatorio) como una prestación adicional al ahorro obligatorio.

- Los Planes cubren a 1,394 millones de participantes, de los cuales solo 1,296 millones son trabajadores activos.

- Las empresas que han establecido algún Plan para sus trabajadores se ubican principalmente en el Distrito Federal (46\%), Nuevo León (11\%) y Estado de México (11\%). En el resto del país se registran muy pocos planes de ahorro.

- El rendimiento real (quitando el efecto de la inflación) ponderado de todos los fondos ha sido de $-2.52 \%$ anual en el último año y de $1.72 \%$ anual en los últimos 5 años.

- Adicionalmente se puede notar que en la dinámica de los planes registrados, estos disminuyeron en los años 2013 y 2014, como se muestra en la Figura 11. 
Figura 11. Planes privados de pensiones registrados ante la CONSAR

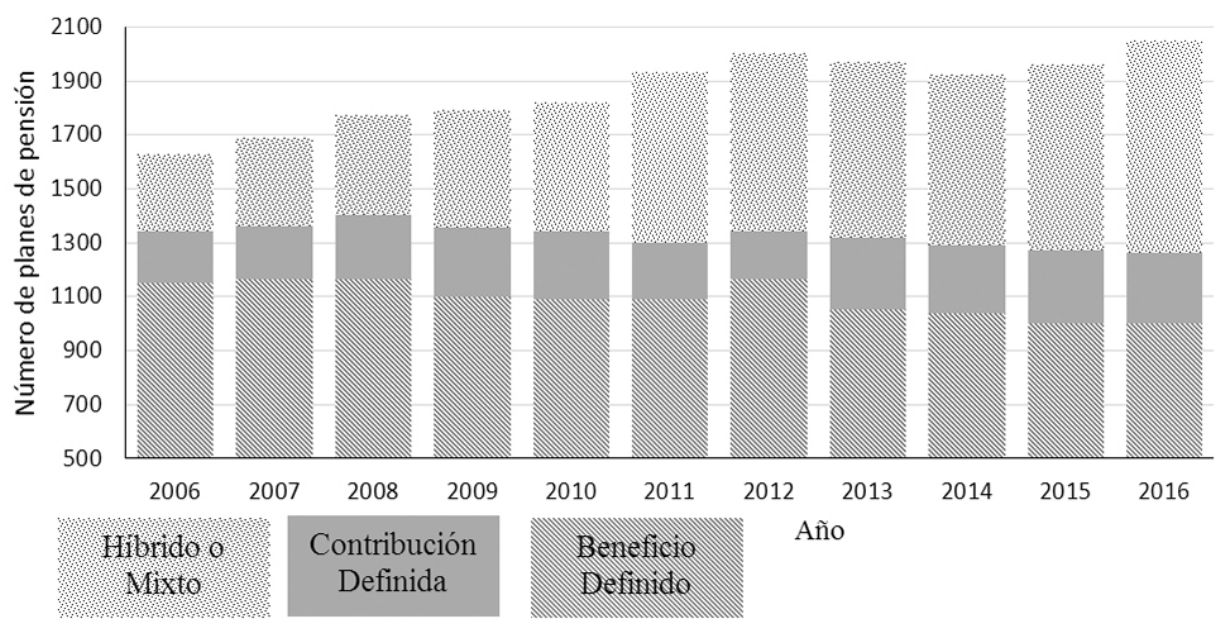

Fuente: CONSAR (2016)

Estadísticas de la Secretaría del Trabajo y Previsión Social (2016) señalan que se tienen registrados ante el IMSS a 18 millones 935 mil 841 trabajadores a noviembre de 2016; por consiguiente, podemos ver que los planes privados de pensiones solo atienden a un $7.3 \%$ de la población asegurada ante el IMSS. Esta baja cobertura de los planes privados es un reflejo de la falta de conciencia en la mayor parte de la sociedad sobre la importancia del ahorro para el retiro. Como resultado de lo anterior, los sistemas de pensiones vigentes en el país son insuficientes. De manera adicional, habría que agregar que de acuerdo con la encuesta nacional de empleo y seguridad social del INEGI (2013), solo el $26 \%$ de la población de adultos mayores percibían una pensión.

Figura 12. Población de 60 años y más que tienen una pensión

Fuente: INEGI (2013)

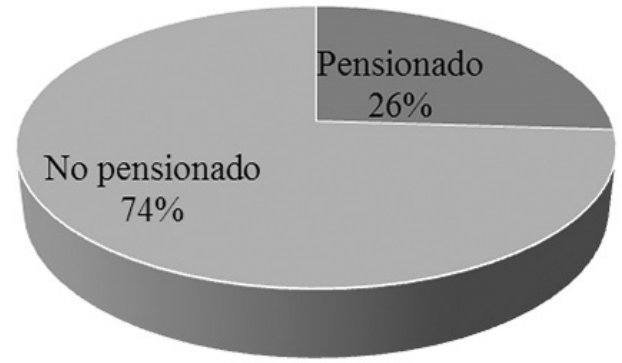


Además, es preocupante el dato de que por cada persona que se integra al mercado laboral con seguridad social, 8 ingresan a uno sin esa prestación.

Lo anterior se agudiza si se considera que el gasto por cuidados médicos y salud se triplica al llegar a la edad de jubilación. A los 34 años de edad representa el $6 \%$ del gasto promedio de una persona, mientras que a los 60 años de edad alcanza el $15 \%$ del gasto promedio de la persona.

Partida (2011) menciona que la mayoría de los trabajadores que no cotizan en los sistemas de pensiones se desenvuelven en condiciones precarias de ocupación características de la informalidad; el resultado es que debido a su baja o nula productividad frenan el crecimiento del PIB y, por ende, la generación de empleos productivos y con prestaciones. La exigua capacidad de ahorro no solo pone en riesgo los activos familiares ante erogaciones imprevistas, sino también evita la acumulación de recursos que permitan sobrellevar dignamente la vejez.

Por los datos que se muestran en esta situación actual del país, es notorio que no estamos aprovechando al máximo la ventana de oportunidad que ofrece el bono demográfico.

\section{Impacto de la educación en el desarrollo de la persona}

Para entender el impacto de la educación en el valor de la persona, es útil definir tres grandes concepciones filosóficas relacionadas con su dignidad y el valor de la sociedad, las cuales nos permitirán conocer la importancia de cada una de estas realidades y justificar las relaciones que se dan entre ambas. La educación tiene que ver directamente con la realidad de la dignificación de la persona, en tanto que la generación de renta (valioso fundamento del ahorro), tiene que ver con la importante realidad de entregarle valor agregado a la sociedad. Ninguna de estas dos realidades, individuo y sociedad, se deben suprimir para beneficiar a cualquiera de las otras dos realidades.

En una visión colectivista extrema, según algunas corrientes del positivismo, el individuo es puro agregado material desprovisto de naturaleza espiritual y trascendente, cuya única importancia radica en el valor utilitario que puede significar para el engrandecimiento de la sociedad.

En una visión filosófica individualista extrema se diviniza a la persona, de modo que la verdad, las soluciones y la razón de vivir se encuentran egoísta y egocéntricamente en el interior de la persona misma, erigiéndose ésta como fin absoluto, demeritando el compromiso del individuo con el prójimo y la sociedad. 
En una visión propia del autor, que pudiéramos llamar convencionalmente humanista, se puede declarar que la sociedad está al servicio del individuo, pero que el individuo pierde sentido de trascendencia si no es útil a la sociedad, luego existe una relación de codependencia con un alto valor de la dignidad de la persona humana. Con esta visión humanista, el autor concibe el modelo de desarrollo individual inserto en el modelo de desarrollo social como una arquitectura iterativa que se retroalimenta constantemente y que no puede prescindir de ninguno de los elementos constructivos que se presentan en la Figura 1.

El fin último de la sociedad es lograr la realización del potencial de libertad del ser humano, como aparece en el cuadrante 1 de la Figura 13. De nada sirve el crecimiento económico de la sociedad y de sus satisfactores si la persona no tiene la libertad de hacer lo que ella decide, la libertad de su espíritu creador y de tener la capacidad de decidir correctamente, por haber recibido una formación educativa previa (Sen, 2000).

Para que la visión anterior se logre es importante que el individuo desarrolle sus capacidades físicas e intelectuales básicas para conseguir sus medios de sustento; entre sus capacidades básicas se encuentra la educación, como se aprecia en el cuadrante 5 de la Figura 13. Una vez que la persona está capacitada para acceder a oportunidades de trabajo y desarrollo, se requiere que la sociedad genere estas oportunidades como aparece en el cuadrante 6 de la Figura 13.

Figura 13. Arquitectura iterativa para el desarrollo humano y social

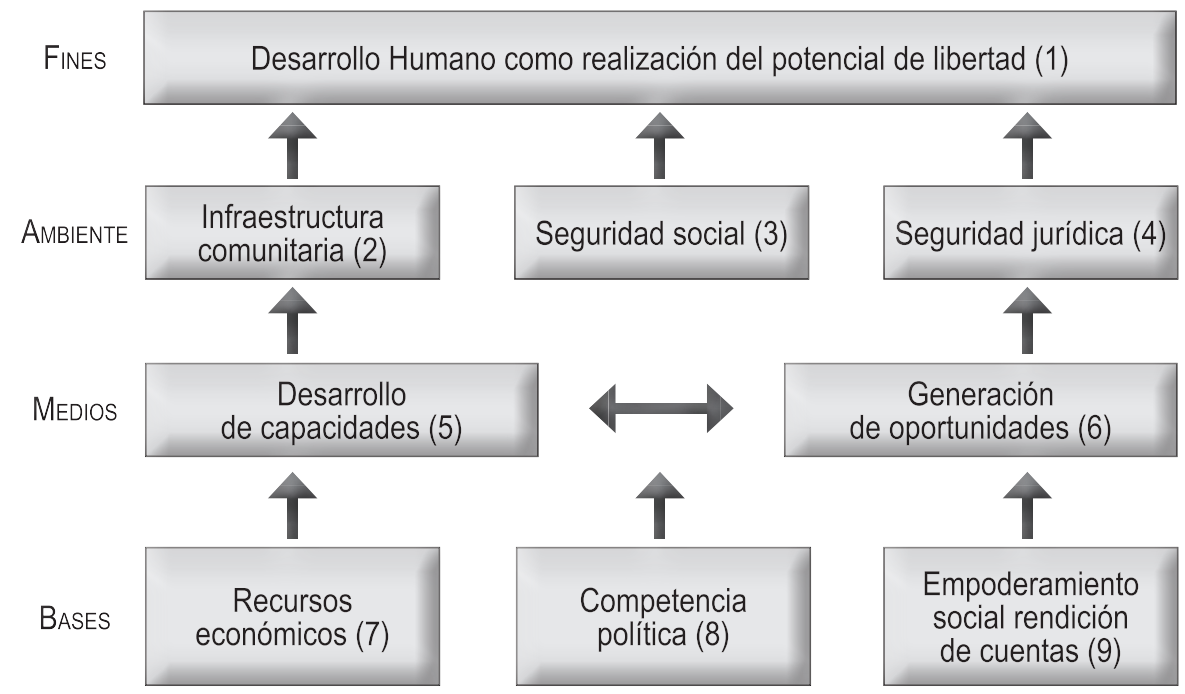

Fuente: Elaboración de Aarón González. Se utilizaron algunos conceptos de la Secretaria de Desarrollo Social (2013). 
La competencia política y la transparencia de la actuación de los servidores públicos, así como la rendición de cuentas del ejercicio del poder, son una base indispensable para proporcionar de manera sostenible y sustentable los medios de desarrollo de capacidades y de generación de oportunidades.

Para que el modelo sea una realidad, se requiere también de un ambiente de seguridad social, jurídica y física de una infraestructura comunitaria que permita el desarrollo de sus integrantes. Ver el cuadrante 2, 3 y 4 de la Figura 13.

La Ley General de Desarrollo Social (2004) señala en su artículo seis: "Son derechos para el desarrollo social la educación, la alimentación, la vivienda, el disfrute de un ambiente sano, el trabajo y la seguridad social".

El Banco Mundial (1990) menciona que: "los países que más éxito han tenido en su lucha contra la pobreza han propugnado por un modelo de crecimiento basado en inversión en capital humano".

Esta visión contrasta con la que finca sus esperanzas en el crecimiento del Producto Interno Bruto (PIB), el avance tecnológico, la modernización de los procesos productivos y sociales.

El enfoque con el que abordamos el tema del desarrollo de la persona nos permite establecer otro orden entre fines y medios: el fin es la consolidación de las libertades individuales y los medios son la infraestructura, la tecnología y el desarrollo económico.

Este enfoque con visión humanista reconoce que no existe otro derecho más fundamental para el ser humano como la libertad.

Por lo tanto, para que se logre un desarrollo pleno del individuo a través de la vivencia de sus libertades, se requiere que la persona esté equipada con capacidades educacionales que le permitan generar renta, pero que también tenga la capacidad reflexiva para vivir plena, consiente y responsablemente sus libertades y tome decisiones que eleven su nivel de vida y bienestar.

Por todo lo anterior, la educación se ha convertido en uno de los principales motores del desarrollo. 


\section{Educación financiera para la vida}

Educar a los adultos para la vida y el trabajo se ha convertido en los últimos años en una de las mayores prioridades de la educación, para fortalecer el diseño de modelos instruccionales eficientes que respondan a las necesidades de un mundo tan cambiante como exigente, de modo que les permita enfrentar de manera exitosa los nuevos retos que nos presenta el siglo XXI.

La educación que impacta directamente el desarrollo de la persona y sus decisiones acertadas para expresarse en esta vida se ha englobado en un concepto que se ha nombrado nacional e internacionalmente como "Modelo de educación para la vida y el trabajo", el cual tiene que ver con la educación a lo largo de la vida.

Comenta Mendoza (2002): "Esto se relaciona con un concepto amplio de sociedad educativa, es decir, la ocasión de aprender y desarrollar capacidades para poder, de manera efectiva, insertarse en otros procesos de desarrollo".

El proceso de desarrollo mencionado debe ser un espacio de reflexión y libertad que permita que el hombre no solo haga o tenga, sino que también sea, se exprese y tome decisiones pertinentes para su vida.

Messina (2002) comenta: "La educación, entonces, es concebida como una estrategia para promover dos pilares: la competitividad internacional de los países y la construcción de la moderna ciudadanía". Por lo tanto la educación debe ser un apoyo que catapulte al individuo para realizarse plenamente y para tomar decisiones acertadas.

Sintetizando lo anterior, la educación debe ser un elemento fundamental para construirnos como sujetos y sociedad. Esto nos lleva a considerar a los cuatro pilares de la educación que menciona Delors en su informe a la UNESCO: "Aprender a conocer, aprender a hacer, aprender a vivir y aprender a ser" (Delors, 1996).

El Gobierno del Estado de Nuevo León (2016), en el Plan Estatal de Desarrollo, expresa en materia educativa su compromiso con la educación durante toda la vida: "En la reforma se integran los temas derivados del Foro Mundial sobre la Educación 2015 de la Organización de las Naciones Unidas para la Educación, la Ciencia y la Cultura (Unesco, por sus siglas en inglés) de Incheon, República de Corea, es decir, garantizar educación inclusiva, equitativa y de calidad, así como promover oportunidades de aprendizaje durante toda la vida, para transformar vidas mediante la educación". 
Es importante mencionar que la educación financiera ha sido definida por la Organización para la Cooperación y Desarrollo Económico (OCDE) como una habilidad para la vida (life skill). La educación debe ser una herramienta para crear ciudadanía previsora y responsable. La OCDE (2013) en su publicación La Educación Financiera en América Latina y el Caribe, menciona lo siguiente:

- En general, se refleja una ignorancia generalizada en la población con respecto a conceptos financieros básicos como inflación, tasa de interés, relación entre riesgo y rentabilidad y sobre el funcionamiento del mercado de capitales.

- Ahorro e inversión. En la mayor parte de la región la población no ahorra para la jubilación.

- El análisis del contexto de América Latina y el Caribe provee la racionalidad del papel de las políticas públicas en el desarrollo económico y social de la región. Entre las herramientas de política seleccionadas, está la educación financiera.

No existe una definición de educación financiera universalmente aceptada, sin embargo, para entrar más específicamente en el tema, a continuación se presenta la definición de la Organización para la Cooperación y el Desarrollo Económicos (OECD): La educación financiera es el proceso por el cual los consumidores/inversionistas financieros mejoran su comprensión de los productos financieros, los conceptos y los riesgos, y, a través de información, instrucción y/o el asesoramiento objetivo, desarrollan las habilidades y confianza para ser más conscientes de los riesgos y oportunidades financieras, tomar decisiones informadas, saber a dónde ir para obtener ayuda y ejercer cualquier acción eficaz para mejorar su bienestar económico (OECD, 2005a).

El Consejo Nacional de Inclusión Financiera en México (CNIF) vierte conceptos adicionales relacionados con la materia y que son muy útiles para delimitar las fronteras de acción e influencia de cada término.

EI CNIF dice: educación financiera (financial education), tiene que ver con la instrumentación de los procesos necesarios para la construcción de estos conocimientos, habilidades y actitudes en las personas; alfabetización financiera (financial literacy), se refiere a contar con los conocimientos y habilidades suficientes para tomar decisiones financieras informadas y, finalmente, las capacidades financieras (financial capabilities), que indican la forma en que las 
personas usan o aplican esos conocimientos y habilidades en su toma de decisiones financieras (Consejo Nacional de Inclusión Financiera en México, 2106).

Sintetizando a la CNIF, la educación (financiera) tiene los siguientes efectos:

- construye alfabetización (financiera), a través de la transferencia de conocimiento,

- con lo anterior, logra un impacto que se manifiesta en el empleo de capacidades (financieras).

En palabras de la OECD, la educación financiera:

- comienza con la transferencia de nociones básicas, como los nombres y características de productos,

- termina con la formación de un entendimiento en la persona que genere cambios positivos en el comportamiento, de modo que gestione sus finanzas adecuadamente.

La utilización de estas capacidades financieras, según la OECD y la CNIF, cuando comentan que ayuda a tomar decisiones financieras informadas para mejorar su bienestar económico, debe traer consigo los siguientes beneficios prácticos a las personas y por lo tanto a sus comunidades:

- Preparación de un presupuesto que se utilice en la racionalidad del gasto cotidiano y que sea un freno para disminuir el consumo innecesario.

- Situación en la que las persones no se sobre endeuden, ni tomen créditos con un costo desmedido en relación al costo del mercado. Un uso adecuado y prudente de las tarjetas de crédito.

- Inversiones prudentes, en las que los excedentes de recursos, resultantes de la sujeción a un presupuesto se canalicen para maximizar su rendimiento, de acuerdo al riesgo que se desee tomar.

- Comportamiento cívico de las personas, utilizando las herramientas para defender sus derechos como consumidores financieros.

- Protección al patrimonio de la familia, a través de la compra de un seguro adecuado a sus necesidades.

- Existencia de un fondo para enfrentar necesidades básicas de la familia, como es la salud, la educación, la casa, etc.

- Existencia de un ahorro que signifique un ingreso digno al momento del retiro laboral de la persona. 
Algunos organismos y empresas han realizado esfuerzos en educación financiera. La estadística de estos esfuerzos aparece en la Figura 14.

Figura 14. Esfuerzos desplegados en educación financiera

Porcentaje de instituciones que tiene programa de educación financiera
Número de instituciones que tienen programa
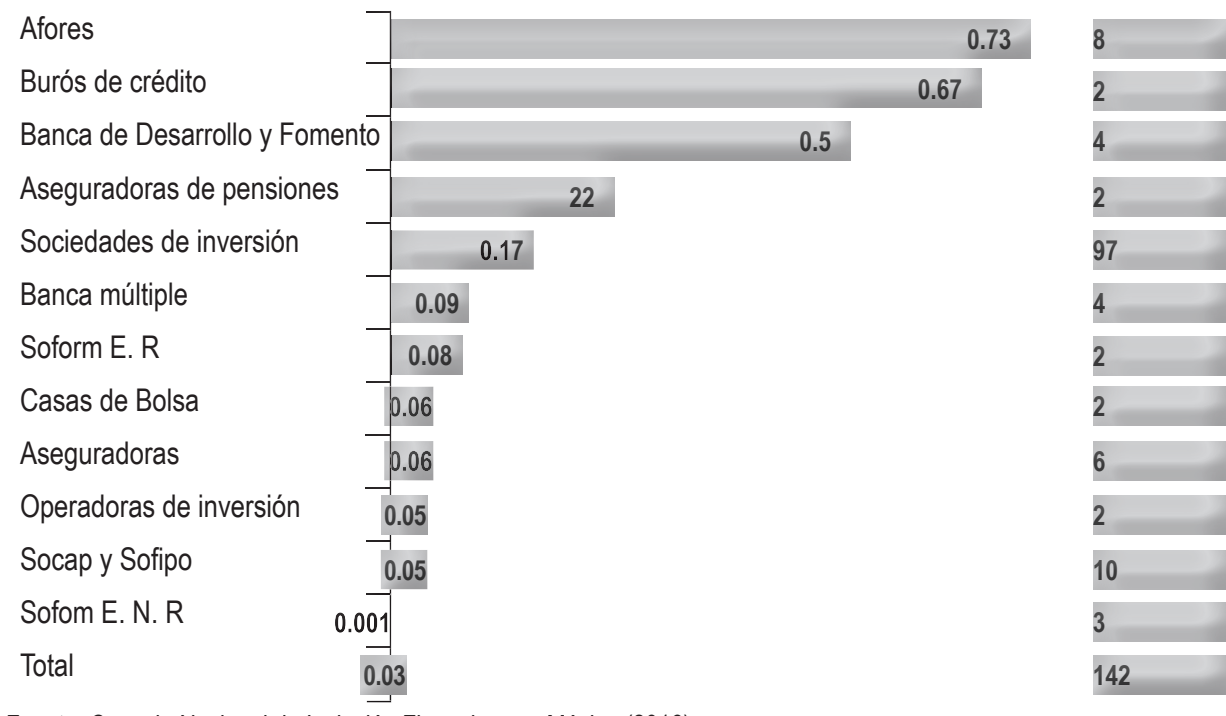

Fuente: Consejo Nacional de Inclusión Financiera en México (2016)

Como se aprecia en la Figura 14, hay instituciones que se han involucrado con mucho compromiso en el proceso de educación, sin embargo, todavía faltan muchas otras que no han participado en estos esfuerzos.

El presente experimento se realizó para conocer en las personas que habitan el área metropolitana de Monterrey y que tienen las características de la muestra:

- El nivel de alfabetización financiera que ha logrado la educación financiera que se ha llevado a cabo.

- El grado de utilización de las capacidades financieras, es decir, si la alfabetización ha logrado un cambio de comportamiento. En otras palabras, se realizó un experimento para observar qué tanto impacto tiene el componente educativo en finanzas para que se logre una real conciencia de la responsabilidad insoslayable que cada uno tiene para hacerse cargo de sus necesidades, cuando llegue a su edad adulta mayor a los 60 años, mostrándolo a través de un ahorro para el retiro. 


\section{Resultados de la investigación}

Los resultados obtenidos en la investigación se pueden observar en la Tabla 3. Se aplicaron 261 instrumentos de medición de educación financiera y tasa de ahorro para el retiro entre nuevoleoneses con vecindad con el área metropolitana de Monterrey. Los individuos a los que se les aplicó el instrumento tienen un ingreso bruto promedio de 38,380 pesos mensuales y un nivel de educación financiera de $68.54 \%$ en un rango de $0 \%$ a $100 \%$.

Ellos declararon que realizan en promedio un ahorro para el retiro de un $3.34 \%$ de sus ingresos mensuales brutos, adicional al ahorro que por ley deben efectuar a través de su cuenta individual en una Siefore. Como se puede apreciar en el coeficiente de determinación $\mathrm{R}^{\wedge 2}$, no existe una correlación que explique que la tasa de ahorro para el retiro tenga un comportamiento matemático que esté en función exclusivamente del nivel de educación financiera de la persona.

Es sorprendente ver que un $52.11 \%$ de la población no realiza ningún tipo de ahorro para el retiro adicional a lo que por ley está obligado a efectuar a través de su cuenta individual obligatoria en una Siefore.

Si de la población total de nuevoleoneses con vecindad con el área metropolitana de Monterrey, uno extrae solo aquellas personas que radican y trabajan en esta zona y que tienen las características de la muestra, podemos observar las mismas conclusiones anteriores.

Con el fin de tener un grupo más uniforme, se seleccionaron aquellas personas que cumplen con las siguientes características:

- Habitan en el área metropolitana de Monterrey.

- Se encuentren laborando.

- Se encuentren casados o viviendo en unión libre con su pareja.

- Con una edad de 30 a 49 años.

- Con ingresos de 30,000 a 50,000 pesos mensuales.

La muestra que se obtuvo con las características anteriores fue de 68 personas, la cual cumple con los parámetros estadísticos para ser representativa. Los resultados de la correlación existente fueron muy similares; no existe una correlación matemática de regresión lineal que explique el comportamiento de la tasa de ahorro para el retiro por el nivel de educación financiera de la persona. 
Es notorio observar que también en este caso se tiene un alto porcentaje que no realiza ningún ahorro para el retiro, ya que se llega a que un $48.53 \%$ de la población objetivo con las características mencionadas, no ahorran para el retiro nada adicional a lo que por ley están obligados a tener en una siefore.

Tabla 3. Estadísticos principales de la medición en campo de la educación financiera y la tasa de ahorro para el retiro para diferentes poblaciones

\begin{tabular}{|c|c|c|c|c|c|c|c|}
\hline $\begin{array}{l}\text { Población } \\
\text { encuestada }\end{array}$ & Muestra & $\begin{array}{l}\text { Media } \\
\text { Ingreso } \\
\text { (miles) }\end{array}$ & $\begin{array}{l}\text { Media } \\
\text { (Educación } \\
\text { financiera) } \\
(\%)\end{array}$ & $\begin{array}{l}\text { Media } \\
\text { ahorro } \\
\text { para el } \\
\text { retiro } \\
(\%)\end{array}$ & $\begin{array}{l}\text { Desv. } \\
\text { Standar } \\
\text { ahorro } \\
\text { para el } \\
\text { retiro } \\
(\%)\end{array}$ & $\begin{array}{l}\text { \% Pobla- } \\
\text { ción con } \\
\text { cero de } \\
\text { ahorro } \\
\text { para el } \\
\text { retiro }\end{array}$ & $\begin{array}{c}\text { Coeficiente } \\
\text { de determi- } \\
\text { nación } \\
\text { R 2 } \\
\text { ahorro retiro } \\
\text { vs. } \\
\text { ed. financiera }\end{array}$ \\
\hline $\begin{array}{l}\text { Población } \\
\text { metropolitana }\end{array}$ & 261 & 38,410 & 68.54 & 3.34 & 6.96 & 52.11 & 0.0 \\
\hline $\begin{array}{l}\text { Población } \\
\text { objetivo }\end{array}$ & 68 & 38,380 & 68.47 & 3.04 & 5.11 & 48.53 & 0.0 \\
\hline
\end{tabular}

Fuente: Elaboración de Aarón González, con base en los instrumentos de medición aplicados en campo.

En la Tabla 4 se analiza la población metropolitana por ingreso bruto mensual que perciben y se puede observar que la media de la educación financiera es mayor en la población que tiene mayores ingresos. Con más claridad se puede apreciar los datos graficados en la Figura 15.

También se puede apreciar en la Figura 15, que la media de la tasa de ahorro para el retiro aumenta en la misma dirección en que aumentan los ingresos de la población (si promediamos la tasa de ahorro de los rangos que se encuentran entre 30,0001 a 50,000 pesos mensuales), que es la misma dirección en que aumenta la educación financiera.

Por lo anterior podemos comentar que, aunque no exista una correlación directa entre la tasa de ahorro para el retiro en función del nivel de la educación financiera, la tasa de ahorro para el retiro sí crece al aumentar dicha educación e ingreso, aunque no crece matemáticamente en un modelo de regresión lineal. 
Tabla 4. Estadísticos principales de la medición en campo de la educación financiera y la tasa de ahorro para el retiro para diferentes niveles de ingreso

\begin{tabular}{|c|c|c|c|c|c|c|c|}
\hline $\begin{array}{l}\text { Población } \\
\text { encuestada }\end{array}$ & Muestra & $\begin{array}{l}\text { Media } \\
\text { Ingreso } \\
\text { (miles) }\end{array}$ & $\begin{array}{l}\text { Media } \\
\text { (Educación } \\
\text { financiera) } \\
(\%)\end{array}$ & $\begin{array}{l}\text { Media } \\
\text { ahorro } \\
\text { para el } \\
\text { retiro } \\
(\%)\end{array}$ & $\begin{array}{l}\text { Desv. } \\
\text { Standar } \\
\text { ahorro } \\
\text { para el } \\
\text { retiro } \\
(\%)\end{array}$ & $\begin{array}{l}\% \text { Pobla- } \\
\text { ción con } \\
\text { cero de } \\
\text { ahorro } \\
\text { para el } \\
\text { retiro }\end{array}$ & $\begin{array}{c}\text { Coeficiente } \\
\text { de determi- } \\
\text { nación } \\
\text { R } 2 \\
\text { ahorro retiro } \\
\text { vs. } \\
\text { ed. financiera }\end{array}$ \\
\hline $\begin{array}{l}\text { Ingreso de } \\
30 \text { mil o me- } \\
\text { nos pesos }\end{array}$ & 84 & 19,760 & 65.05 & 2.12 & 4.39 & 59.52 & 0.0 \\
\hline $\begin{array}{l}\text { Ingreso de } 30 \\
\text { mil un pesos } \\
\text { a } 40 \text { mil }\end{array}$ & 87 & 35,000 & 66.11 & 3.74 & 7.28 & 49.43 & 0.0 \\
\hline $\begin{array}{l}\text { Ingreso de } 40 \\
\text { mil un pesos } \\
\text { a } 50 \text { mil }\end{array}$ & 38 & 45,000 & 70.00 & 2.36 & 4.68 & 63.16 & 0.0 \\
\hline $\begin{array}{l}\text { Ingreso de } 50 \\
\text { mil un pesos } \\
\text { a } 60 \text { mil }\end{array}$ & 24 & 55,000 & 76.83 & 5.47 & 7.28 & 37.50 & 0.0 \\
\hline $\begin{array}{l}\text { Ingreso de } \\
60 \text { mil uno } \\
\text { o más pesos }\end{array}$ & 28 & 81,790 & 77.43 & 5.27 & 12.23 & 35.71 & 0.0 \\
\hline
\end{tabular}

Fuente: Elaboración de Aarón González, con base en los instrumentos de medición aplicados en campo.

Figura 15. Medias de educación financiera vs. Medias de ahorro para el retiro

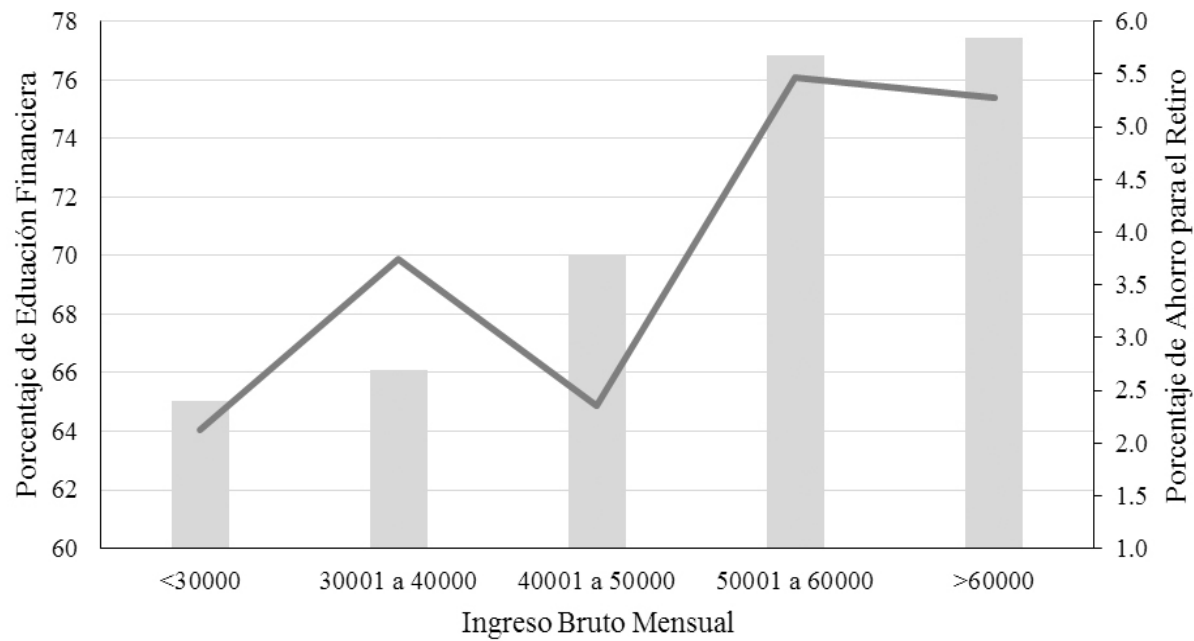

$\%$ Educación Financiera $\quad \%$ Ahorro

Fuente: Elaboración de Aarón González, con base en los instrumentos de medición aplicados en campo. 


\section{Discusión}

Por lo anterior, tenemos suficientes elementos para decir que la hipótesis de estudio se rechaza en la muestra seleccionada, ya que el modelo estadístico al obtener una $\mathrm{R}^{\wedge 2}$ de 0.0 nos brinda información suficiente para determinar que la variable educación financiera por sí sola no influye de manera directa con una pendiente "m" en un modelo de regresión lineal, con el nivel de la tasa de ahorro para el retiro.

Sin embargo, es muy importante observar, según se aprecia en la Figura 15, que, aunque no exista una regresión lineal directa, al aumentar el nivel de educación financiera, también se aumenta la tasa de ahorro para el retiro.

De cualquier forma es importante apuntar las siguientes observaciones:

- Un nivel de educación financiera de 65, en una escala de 0 a $100 \%$, para una población con ingresos inferiores a los 30,000 pesos mensuales, se considera baja.

- Derivado del punto anterior, esta es una razón, entre otras, por la que la media de la tasa de ahorro para el retiro adicional a las aportaciones obligatorias por ley en las cuentas individuales, también es baja, $2.12 \%$ del sueldo bruto mensual, para personas con ingresos menores a 30,000 pesos.

- La media de la tasa de ahorro para el retiro se muestra muy baja porque un $59.52 \%$ de estas personas no ahorran ni un peso para el retiro, ya que tienen un ahorro del $0 \%$.

- Haciendo eco de las palabras y conceptos del Consejo Nacional de Inclusión Financiera en México (2016): la educación financiera pudiera estar construyendo alfabetización financiera, pero esto no garantiza que exista un empleo de capacidades financieras. Dicho en palabras propias, la transferencia de conocimientos por si solos no garantiza un cambio de comportamiento de la persona en su toma de decisiones.

- En este sentido, la OECD (2013) menciona que: la educación financiera es un proceso necesario, pero no suficiente, para empoderar a los consumidores financieros, y es a menudo un componente de una serie de políticas que constituyen el marco para la participación de los individuos en el mercado financiero, el cual está compuesto por la educación financiera, la inclusión financiera y la protección del consumidor financiero. 
- Abonando sobre lo último, es importante mencionar que la falta de ahorro voluntario para el retiro pudiera no solo deberse a la falta de una cultura de previsión, sino también por la incapacidad que existe de generar un ahorro por razón del bajo nivel de los sueldos.

Por las observaciones expresadas, actualmente se refleja en el país una escasa acumulación de recursos en las cuentas individuales, debido al bajo nivel de aportaciones voluntarios. Lo anterior provoca que no se logre aumentar la tasa de reemplazo, que es el porcentaje que representa la pensión sobre el ingreso percibido por el trabajador antes de jubilarse.

En mayo de 2010, por invitación del Banco Mundial, la Comisión Nacional para la Protección y Defensa de los Usuarios de Servicios Financieros (Condusef) y la Comisión Nacional Bancaria y de Valores (CNBV) participaron, junto con otros ocho países, en el proyecto "Medición de las capacidades financieras". Entre los hallazgos encontrados sobre los hábitos de los entrevistados en el manejo de dinero, destacaron lo siguiente:

- Más del $80 \%$ desconoce exactamente cuánto dinero gastó la semana anterior y cuánto gasta diariamente. Solo el $20 \%$ de la población lleva un control de sus gastos.

- El 30 \% reconoció que pide prestado, regular u ocasionalmente, para cubrir sus necesidades alimentarias u otras básicas.

- Respecto al crédito, $34 \%$ de los usuarios de tarjetas de crédito bancarias no conocen su tasa de interés y el $36 \%$ de los usuarios no conoce las comisiones.

\section{Conclusiones}

Es importante mencionar que la educación financiera ha cobrado gran relevancia a nivel mundial. En tanto no se logre empoderar al ciudadano en sus finanzas para que pueda tomar decisiones responsables, se tendrá un problema latente de proporciones sumamente elevadas, ya que el Estado no tendrá la capacidad de tutorar y cuidar la vejez de todos los ciudadanos.

La alfabetización financiera y el desarrollo de capacidades financieras lograrán que el ciudadano consiga una mejor asignación de sus recursos en la compra de satisfactores y reducirá el riesgo de impago al sistema financiero, lo que le permitirá a la sociedad un crecimiento económico más armonioso. 
Los resultados de los diferentes estudios realizados nos manifiestan la importancia de aumentar el proceso de educación financiera. En tanto el ciudadano no tome las riendas de su vida y el Estado le proporcione los medios para que esto se logre, el futuro económico de todo el país será de resultados inciertos e indeseados.

Por último, pero de altísima importancia, se debe reflexionar sobre la importancia de que el proceso de educación financiera comience desde edades tempranas del niño, de modo que se logre impactar su comportamiento en relación a la importancia de tener un ahorro, con el fin de lograr pasar de la etapa de transferencia de conocimientos (alfabetización financiera) a la etapa de cambio de comportamientos, logrando una cultura del ahorro y una cultura de previsión (capacidades financieras).

\section{Referencias}

Banco Mundial. (2001). Informe sobre el desarrollo mundial 2000 / 2001: lucha contra la pobreza, enhttp://documentos.bancomundial.org/curated/es/509031468137396214 /Informe-sobre-el-desarrollo-mundial-2000-2001-lucha-contra-la-pobreza

Bloom, David E. y G. Jeffrey Williamson (1998). Demographic Transitions and Economic Miracles in Emerging Asia. Word Bank Economic Review, 12(3).

Bloom, David E., David Canning y Jaypee Sevilla (2003). The demographic dividend. A new perspective on the economic consequences of population change. Santa Monica: Rand Corporation.

Coale, Ansley J. y Edgar M. Hoover (1958). Population frowth and eonomic development in low-income countries. Princeton: Princeton University Press.

Coale, Ansley J. y Susan C. Atkins (1986). The decline of fertility in Europe. Princeton: Princeton University Press.

Cochran, W. \& Cox, G. (1992). Experimental designs (2a. ed.). Nueva York: Wiley \& Sons. CONSAR. (2016). Estadística del Registro Electrónico de Planes Privados de Pensiones 2016, en http://www.gob.mx/cms/uploads/attachmentfile/129872/estadist_ppp_ 206.pdf

Consejo Nacional de Población. (2004). Envejecimiento de la población de México : reto del Siglo XXI, en http://www.conapo.gob.mx/es/CONAPO/Envejecimiento_de_la_poblacion_de_Mexico_reto_del_Siglo_XXI

Consejo Nacional de Población. (2006). Proyecciones de la población de México 2005-2050, en http://www.alianzacivica.org.mx/guia_transparencia/Files/pdf/desarrollo/14_ PROYECCIONESDELAPOBLACIONDEMEXICO/14_PROYECCIONESDELAPOBLACIONDEMEXICO.pdf 
Consejo Nacional de Inclusión Financiera en México. (2016). Reporte Nacional de Inclusión Financiera, en http://www.cnbv.gob.mx/Inclusi\%C3\%B3n/Documents/Reportes\%20 de\%20IF/Reporte\%20de\%20Inclusion\%20Financiera\%207.pdf

Delors, J. (1996). La educación encierra un tesoro. Madrid: Grupo Santillana.

Gobierno del Estado de Nuevo León. (2016). Plan Estatal de Desarrollo 2016-2021, en

http://www.nl.gob.mx/publicaciones/plan-estatal-de-desarrollo-2016-2021

Hernández Sampieri, R., Fernández Collado, C. \& Baptista Lucio, P. (2003). Metodología de la investigación ( $3^{\mathrm{a}}$ ed.). México: McGraw-Hill.

INEGI. (2013). Encuesta nacional de empleo y seguridad social, de http://www.beta.inegi.org. $\mathrm{mx} / \mathrm{app} / \mathrm{biblioteca/ficha.html?upc=702825058777}$

INEGI. (2015). Encuesta Intercensal 2015, en http://www.inegi.org.mx/default.aspx

Ley General de Desarrollo Social. (2004). Artículo VI, en http://www.dof.gob.mx/nota_detalle. php?codigo $=676752 \&$ fecha $=20 / 01 / 2004$

Mason, Andrew, Ronald Lee, An-Chi Tung, Mun-Sim Lai y Tim Miller (2006). Population aging and intergenerational transfers: Intoducing age into national accounts. Cambridge:

National Bureau of Economic Research.

Mejía, Ivan y Octavio Mojarro (2000). Efectos de la transición demográfica sobre el ahorro y la inversión en México. Consejo Nacional de Población.

Mendoza, S. E. (2002, octubre). Modelo de educación para la vida y el trabajo. Documento presentado en el Seminario de la Política Social Hoy. Nuevas Perspectivas Desde América Latina y el Caribe, México, D.F.

Messina G. (2002, octubre). "Satisfacción de necesidades básicas de aprendizaje de la población en extrema pobreza". Documento presentado en el Seminario de la Política Social Hoy. Nuevas Perspectivas Desde América Latina y el Caribe, México, DF.

OCDE. (2013). La Educación Financiera en América Latina y el Caribe, en http://www.oecd. org/daf/fin/finan-cial-education/OECD_CAF_Financial_Education_Latin_America ES.pdf.

OECD (2005a), Improving Financial Literacy: Analysis of Issues and Policies. OECD Publishing.

Partida, Virgilio (2011). Temas relevantes y aplicaciones prácticas en materia de retiro y jubilación en México. México: IMEF, LOCKTON, ERNST \& YOUNG

Population Division of the Department of Economic and Social Affairs of the United Nations Secretariat. (2002). World Population Prospects. The 2002 Revision, en http:/www.un.org/esa/population/publi-cations/wpp2002/WPP2002_VOL_3.pdf

Population Division of the Department of Economic and Social Affairs of the United Nations Secretariat. (2012). World population prospects. The 2012 revision, en http://www.un.org/en/development/desa/population/publications/pdf/ageing/ WPA2015_Report.pdf

Ritchey, F. (2002). Estadística para las ciencias sociales: el potencial de la imaginación estadística. México: McGraw-Hill. 
Secretaría del Trabajo y Previsión Social. (2016). Estadísticas del Sector, en http://www.stps. gob.mx/bp/secciones/conoce/areas_atencion/areas_atencion/web/menu_infsector. html

Secretaría de Desarrollo Social. (2013). Programa Sectorial de Desarrollo Social 2013-2018, en http://www.sedesol.gob.mx/work/models/SEDESOL/Transparencia/Documentos Oficiales/Programa_Sectorial_Desarrollo_Social_2013_2018.pdf

Sen, A. (2000). Desarrollo y libertad. Barcelona. Ed. Planeta. 